\title{
Development and evaluation of floating microspheres of verapamil hydrochloride
}

\author{
Yuveraj Singh Tanwar*, Pushpendra Singh Naruka, Garima Rani Ojha \\ Bhupal Nobles' College of Pharmacy, Udaipur-313001, Rajasthan, India
}

*Correspondence:

Dr. Y.S. Tanwar

Department of Pharmaceutics,

Bhupal Nobles' College of Pharmacy,

Udaipur-313 001, Rajasthan, India.

E-mail: yuveraj2000@yahoo.co.in
The present study involves preparation and evaluation of floating microspheres of verapamil hydrochloride for improving the drug bioavailability by prolongation of gastric residence time. Cellulose acetate, acrycoat S100 and eudragit S100 microspheres loaded with verapamil hydrochloride were prepared by solvent diffusionevaporation method. The microspheres had smooth surfaces, with free-flowing and good-packing properties. The yield of the microspheres was up to $70.51 \%$ and cellulose acetate microspheres entrapped the maximum amount of the drug. Scanning electron microscopy confirmed their hollow structures with sizes in the range 251.80 to $350.75 \mu \mathrm{m}$. The prepared microspheres exhibited prolonged drug release and remained buoyant for more than $12 \mathrm{~h}$. Radiographic images of dog stomach revealed that cellulose acetate microspheres loaded with barium sulphate floated on the gastric fluid for about $3.2 \mathrm{~h}$. In vitro release studies demonstrated non-Fickian diffusion of drug from the microspheres.

\section{INTRODUCTION}

Oral delivery of drugs is by far the most preferable route of drug delivery due to ease of administration, patient compliance and flexibility in formulation etc. From immediate release to site-specific delivery, oral dosage forms have really progressed. However, it is a wellaccepted fact that it is difficult to predict the real in vivo time of release with solid, oral controlled release dosage forms. Thus, drug absorption in gastrointestinal (GI) tract may be very short and highly variable in certain circumstances (Garg, Sharma, 2003; Singh, Kim, 2000).

Several difficulties are faced in designing controlled release systems for better absorption and enhanced bioavailability. Various attempts have been made to prolong the retention time of the dosage form in the stomach. One such method is the preparation of a device that remains buoyant in the stomach contents due to its lower density than that of the gastric fluids (Desai, Bolton, 1993; Whitehead et al., 1998). Single-unit formulations are associated with problems such as sticking together or being obstructed in the gastrointestinal tract, which may have a potential danger of producing irritation. On the other hand, a floating system made of multiple unit forms has relative merits compared to a single unit preparation. Indeed, the gastric emptying of a multiparticulate floating system would occur in consistent manner with small individual variations. On each subsequent gastric emptying, sunk particles will spread out over a large area of absorption sites, increasing the opportunity for drug release profile and 
absorption in a more or less predictable way. Moreover, since each dose consists of many subunits, the risk of dose dumping is reduced (Iannuccelli et al., 1998; Kawashima et al., 1992).

Verapamil hydrochloride, a calcium channel blocker is widely used for the treatment of hypertension, angina pectoris, supraventricular tachycardia and myocardial infraction. It is completely absorbed (90\%) from the gastrointestinal tract after oral administration but has very low bioavailability of $22 \pm 8 \%$. The low bioavailability is owing to the rapid biotransformation in the liver with a biological half-life of $4.0 \pm 1.5$ hours. The short biological half-life and poor bioavailability of drug favours development of sustained release formulation (Passerini et al., 2003; Thummel et al., 2001).

The objective of the present work was to develop and characterize floating microspheres of verapamil hydrochloride, which after oral administration could prolong the gastric residence time and increase the drug bioavailability.

\section{MATERIAL AND METHODS}

Verapamil hydrochloride was received as a gift sample from Nicholas Piramal (India) Ltd., Mumbai. Torrent Pharmaceuticals Ltd., Ahmedabad, India provided Eudragit S100. Cellulose Acetate was procured from Ottokemi, Mumbai, India. Acrycoat S100 was purchased from Corel Pharma. Chem., Ahmedabad, India. Polyvinyl alcohol, hydrochloric acid and tween 80 were procured from Central Drug House Ltd., Delhi, India. Dichloromethane, ethanol, acetone, ethyl acetate and isopropyl alcohol were purchased from E. Merck (India) Ltd., Mumbai. All the other chemicals used were of analytical grade.

\section{Preparation of floating microspheres}

Floating microspheres loaded with verapamil hydrochloride were prepared using solvent diffusionevaporation method (Soppimath et al., 2001) using cellulose acetate (F1), eudragit S100 (F2) and acrycoat S100 (F3). Drug and polymer in proportion of 1:2 were dissolved in 1:1 mixture of solvent system of ethyl acetate and acetone for cellulose acetate, dichloromethane and ethanol for acrycoat S100; dichloromethane, ethanol and isopropyl alcohol (1:1:1) for eudragit S100. This clear solution was poured slowly in a thin stream into the aqueous solution of $0.05 \%$ polyvinyl alcohol. The emulsion was continuously stirred for $3 \mathrm{~h}$ at a speed of $500 \mathrm{rpm}$ at $27 \pm 2{ }^{\circ} \mathrm{C}$. The floating microspheres were collected by decantation, while the non-floating microspheres were discarded. The microspheres were dried overnight at $40 \pm 2^{\circ} \mathrm{C}$ and stored in desiccator.

\section{Size and shape of microspheres}

The size of microspheres was determined using microscope (Olympus NWF 10x, Educational Scientific Stores, India) fitted with an ocular micrometer and stage micrometer. Scanning electron microscopy (SEM) (Leo 430, Leo Electron Microscopy Ltd, Cambridge, England) was performed to characterize the surface of the formed microspheres. Microspheres were mounted directly onto sample stub and coated with gold film $(\sim 200 \mathrm{~nm})$ under reduced pressure $(0.133 \mathrm{~Pa})$.

\section{Flow properties}

The flow properties of microspheres were characterized in terms of angle of repose, carr index and hausner ratio (Sinha et al., 2005). For determination of angle of repose $(\theta)$, the microspheres were poured through the walls of a funnel, which was fixed at a position such that its lower tip was at a height of exactly $2.0 \mathrm{~cm}$ above hard surface. The microspheres were poured till the time when upper tip of the pile surface touched the lower tip of the funnel. The $\tan ^{-1}$ of the height of the pile / radius of its base gave the angle of repose.

Microspheres were poured gently through a glass funnel into a graduated cylinder cut exactly to $10 \mathrm{ml}$ mark. Excess microspheres were removed using a spatula and the weight of the cylinder with pellets required for filling the cylinder volume was calculated. The cylinder was then tapped from a height of $2.0 \mathrm{~cm}$ until the time when there was no more decrease in the volume. Bulk density $\left(\rho_{b}\right)$ and tapped density $\left(\rho_{t}\right)$ were calculated. Hausner ratio $\left(\mathrm{H}_{\mathrm{R}}\right)$ and carr index $\left(\mathrm{I}_{\mathrm{C}}\right)$ were calculated according to the two equations given below:

$$
\begin{aligned}
\mathrm{H}_{\mathrm{R}} & =\rho_{\mathrm{t}} / \rho_{\mathrm{b}} \\
\mathrm{I}_{\mathrm{C}} & =\left(\rho_{\mathrm{t} \%} \rho_{\mathrm{b}}\right) / \rho_{\mathrm{t}}
\end{aligned}
$$

\section{In vitro buoyancy}

Microspheres (300mg) were spread over the surface of a USP XXIV dissolution apparatus type II filled with $900 \mathrm{~mL}$ of $0.1 \mathrm{~N}$ hydrochloric acid containing $0.02 \%$ tween 80 . The medium was agitated with a paddle rotating at $100 \mathrm{rpm}$ for $12 \mathrm{~h}$. The floating and the settled portions of microspheres were recovered separately. The microspheres were dried and weighed. Buoyancy percentage was calculated as the ratio of the mass of the microspheres that remained floating and the total mass of the microspheres (Srivastava et al., 2005). 


\section{In vivo floating behaviour}

Healthy beagle dogs weighing approximately $15 \mathrm{~kg}$ was used to assess in vivo floating behaviour. Ethical clearance for the handling of experimental animals was obtained from the institutional animal ethical committee (IAEC) constituted for the purpose. The animals were fasted for $12 \mathrm{~h}$ and the first X-ray photographed to ensure absence of radio opaque material in the stomach. The dogs were made to swallow barium sulphate loaded cellulose acetate microspheres with $100 \mathrm{ml}$ of water. During the experiment dogs were not allowed to eat but water was provided ad libitum. At predetermined time intervals the radiograph of the abdomen was taken using an X-ray machine (Medford).

\section{Incorporation efficiency (IE)}

To determine incorporation efficiency floating microspheres were dissolved in a minimal amount of dichloromethane and the drug was extracted into a suitable aqueous media ( $0.1 \mathrm{~N}$ hydrochloric acid) by evaporating dichloromethane. The solution was filtered through $0.45 \mathrm{~m}$ membrane, diluted suitably and analyzed for drug content spectrophotometrically at $278 \mathrm{~nm}$ using $0.1 \mathrm{~N}$ hydrochloric acid as blank.

\section{In vitro drug release studies}

The drug release was studied using a USP 24 dissolution apparatus type I (Veego Scientific, Mumbai) at $100 \mathrm{rpm}$ in $0.1 \mathrm{~N}$ hydrochloric acid as dissolution medium $(900 \mathrm{~mL})$ maintained at $37 \pm 1^{\circ} \mathrm{C}$. A sample $(10 \mathrm{~mL})$ of the solution was withdrawn from the dissolution apparatus hourly and the samples were replaced with fresh dissolution medium. The samples were filtered through a $0.45 \mu$ membrane filter and diluted to a suitable concentration with $0.1 \mathrm{~N}$ hydrochloric acid. Absorbance of these solutions was measured at $278 \mathrm{~nm}$ using a Thermospectronic-1 UV/Vis double-beam spectrophotometer. Cumulative percentage drug release was calculated using an equation obtained from a standard curve.

\section{RESULTS AND DISCUSSION}

The floating microspheres of verapamil hydrochloride were prepared by solvent diffusion-evaporation method. The results of the physico-chemical characterization are shown in Table I. The prepared floating microspheres were found to be discrete, spherical and free flowing. The mean arithmetic diameter varied between 251.80 to $350.75 \mu \mathrm{m}$; eudragit S100 microspheres representing the least size and cellulose acetate microspheres the largest size. Surface morphology characteristics were studied using SEM (Figure 1). SEM indicated that the prepared microspheres are spherical with smooth surface; distinct pores are evident on the surface of microspheres, which will be responsible for the release. The photomicrographs also showed presence of loose crystals of drug on the surface of few microspheres.

Angle of repose, hausner ratio, and carr index were determined to predict flowability. A higher Hausner ratio indicates greater cohesion between particles while a high Carr index is indicative of the tendency to form bridges. The prepared microspheres exhibited good flow properties and can be arranged as: F1 $>$ F3 $>$ F2. The percentage yield of floating microspheres was found to be $68.90,63.60$ and $70.51 \%$ for F1, F2 and F3 respectively. Percentage incorporation efficiency was in the range of $64.31 \%$ to $84.62 \%$, cellulose acetate microspheres entrapped maximum amount of the drug.

To assess the floating properties, the microspheres were placed in $0.1 \mathrm{~N}$ hydrochloric acid containing surfactant tween $80(0.02 \% \mathrm{v} / \mathrm{v})$, to simulate gastric conditions. The use of tween 80 was to account for the wetting effect of the natural surface-active agents in the GIT. The microspheres floated for prolonged time over the surface of the dissolution medium without any apparent gelation. Buoyancy percentage of the microspheres was in the range of 46.19 to $69.59 \%$ at the end of $12 \mathrm{~h}$. The nature of the polymer influenced the floating behaviour of the microspheres. The in vivo floating behaviour of cellulose acetate microspheres loaded with barium sulphate was investigated by radiographic images (X-ray photographs) of dog's stomach at periodic time intervals. To make the

TABLE I - Characterization of verapamil hydrochloride floating microspheres

\begin{tabular}{lcccccc}
\hline Code & $\begin{array}{c}\text { Mean particle } \\
\text { size }(\mu \mathrm{m})\end{array}$ & $\begin{array}{c}\text { Angle of repose } \\
(\theta)\end{array}$ & $\begin{array}{c}\text { Hausner ratio } \\
\left(\mathrm{H}_{\mathrm{R}}\right)\end{array}$ & $\begin{array}{c}\text { Carr index } \\
\left(\mathrm{I}_{\mathrm{C}}\right)\end{array}$ & $\begin{array}{c}\text { Buoyancy } \\
(\%)\end{array}$ & $\begin{array}{c}\text { Incorporation } \\
\text { efficiency }(\%)\end{array}$ \\
\hline F1 & $350.75 \pm 5.30$ & $24.42^{\circ} \pm 0.03$ & $1.152 \pm 0.045$ & $0.141 \pm 0.017$ & $69.92 \pm 1.27$ & $84.62 \pm 4.05$ \\
F2 & $307.85 \pm 9.63$ & $29.46^{\circ} \pm 0.28$ & $1.180 \pm 0.051$ & $0.153 \pm 0.010$ & $46.19 \pm 1.62$ & $64.31 \pm 3.61$ \\
F3 & $251.80 \pm 7.27$ & $28.29^{\circ} \pm 0.11$ & $1.165 \pm 0.022$ & $0.149 \pm 0.015$ & $60.04 \pm 1.41$ & $72.29 \pm 1.07$ \\
\hline
\end{tabular}

Results are expressed as Mean \pm S.D. $(n=5)$. 

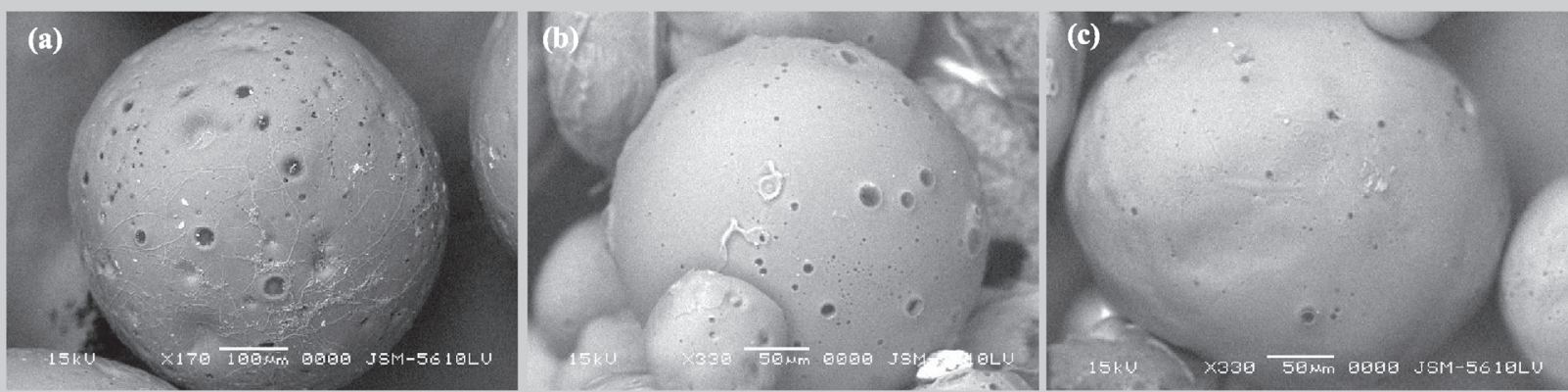

FIGURE 1 - SEM photomicrographs of floating microspheres of verapamil hydrochloride.

microspheres X-ray opaque barium sulphate was incorporated into the microspheres. The amount of X-ray opaque material in these microspheres was sufficient to ensure visibility by X-ray but at the same time the amount of barium sulphate (10mg per $\mathrm{g}$ of microspheres) was low enough to enable the microspheres to float. The duration of floating in vitro was more than $8 \mathrm{~h}$. The microspheres did not adhere to the gastric mucous and floated on the gastric fluid for about $3.2 \pm 0.05 \mathrm{~h}$ (Figure 2).

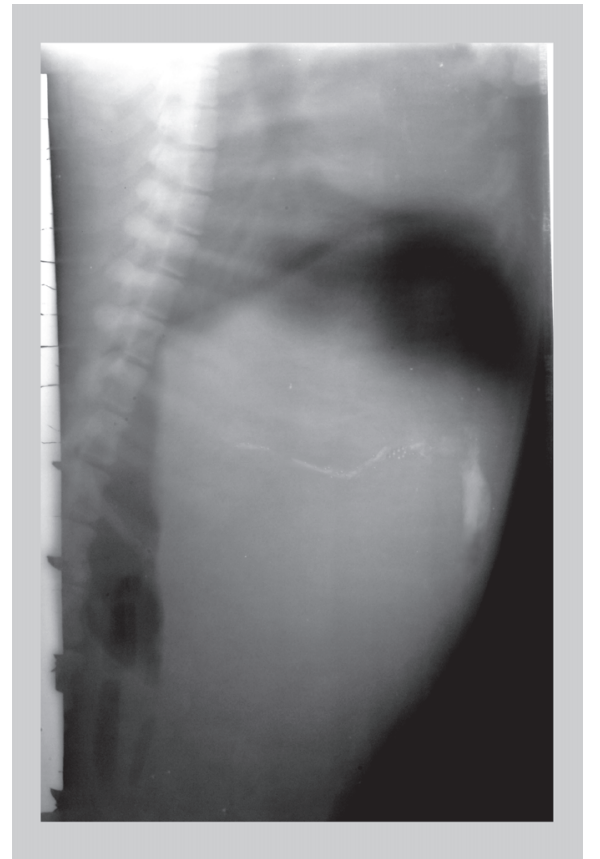

FIGURE 2 - In vivo floating behaviour of cellulose acetate microspheres.

The drug release from floating microspheres was found to be $95.52,83.51$ and $72.76 \%$ at the end of $12 \mathrm{~h}$ for F1, F2 and F3 respectively (Figure 3). The data obtained from in vitro dissolution studies were fitted to zero-order, first-order and Korsemeyer-Peppas equations (Table II).
The zero-order plots were found to be fairly linear as indicated by their high regression values of $0.989,0.981$ and 0.985 for F1, F2 and F3 respectively. To confirm the exact mechanism of drug release, the data were fitted according to Korsemeyer-Peppas equation (Korsemeyer et al., 1983). Korsmeyer et al.(1983) used a simple empirical equation to describe general solute release behaviour from controlled release polymer matrices:

$$
m / m_{T}=\mathrm{k} \mathrm{t}^{n}
$$

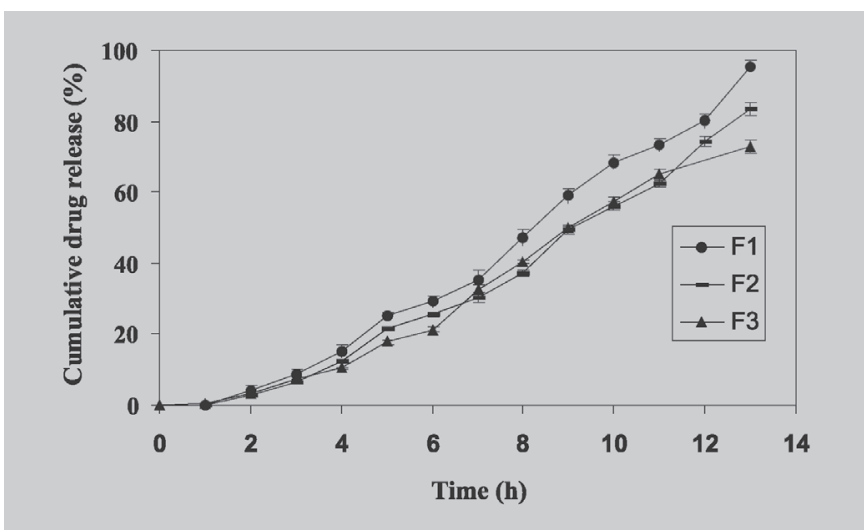

FIGURE 3 - In vitro release profile of verapamil hydrochloride microspheres $(\mathrm{n}=5)$.

TABLE II - Kinetics of in vitro release from floating microspheres of verapamil hydrochloride

\begin{tabular}{lcccccc}
\hline Code & \multicolumn{2}{c}{$\begin{array}{l}\text { Zero- } \\
\text { order }\end{array}$} & \multicolumn{2}{c}{$\begin{array}{c}\text { First- } \\
\text { order }\end{array}$} & \multicolumn{2}{c}{ Korsemeyer- } \\
& Peppas \\
& $\mathrm{k}_{0}\left(\mathrm{mg}_{\mathrm{h}} \mathrm{h}^{-1}\right)$ & $\mathrm{R}^{2}$ & $\mathrm{k}_{1}\left(\mathrm{~h}^{-1}\right)$ & $\mathrm{R}^{2}$ & $\mathrm{n}$ & $\mathrm{R}^{2}$ \\
\hline F1 & 8.003 & 0.989 & -0.224 & 0.860 & 0.876 & 0.994 \\
F2 & 7.034 & 0.981 & -0.128 & 0.856 & 0.830 & 0.987 \\
F3 & 6.269 & 0.985 & -0.119 & 0.875 & 0.714 & 0.990 \\
\hline
\end{tabular}


where $m_{t} / m_{T}$ is fraction of drug released, $\mathrm{k}$ is kinetic constant, $\mathrm{t}$ is release time and $n$ is the diffusional exponent for drug release. Peppas stated that the above equation could adequately describe the release of solutes from slabs, spheres, cylinders and discs, regardless of the release mechanism. The value of ' $n$ ' gives an indication of the release mechanism; when $n=1$, the release rate is independent of time (zero-order) (case II transport), $n=0.5$ for Fickian diffusion and when $0.5<n<1.0$, diffusion and non-Fickian transport are implicated. Lastly, when $n>1.0$ super case II transport is apparent. ' $n$ ' is the slope value of $\log m / m_{T}$ versus log time curve.

Regression analysis was performed and regression values ' $\mathrm{R}^{2}$ ' were 0.990 to 0.994 for different formulations. Slope values $(0.5<\mathrm{n}<1.0)$ suggest that the release of verapamil hydrochloride from floating microspheres followed non-Fickian diffusion mechanism. There is significant difference in the release rate from formulations prepared from different polymers $(p<0.01)$. The type of polymer significantly influenced the drug release rate, in the order: Cellulose acetate $>$ Acrycoat S100 > Eudragit S100.

\section{CONCLUSIONS}

Floating microspheres of verapamil hydrochloride were prepared by a solvent diffusion-evaporation method. The nature of polymer influenced the physical characteristics as well as floating behaviour of the microspheres. In vitro buoyancy and in vivo studies confirmed the excellent floating properties of cellulose acetate microspheres. The drug release was sufficiently sustained and non-Fickian transport of the drug from floating microspheres was confirmed. Hence the floating microspheres of verapamil hydrochloride prepared with cellulose acetate, may provide a convenient dosage form for achieving best performance regarding flow, release and floating properties. Further, their potential to improve verapamil hydrochloride bioavailability in humans need to be investigated in further studies.

\section{RESUMO}

\section{Desenvolvimento e avaliação de microesferas flutuan- tes de cloridrato de verapamil}

O presente estudo envolve a preparação e a avaliação de microesferas flutuantes de cloridrato de verapamil para o melhoramento da biodisponibilidade do fármaco por meio do prolongamento do tempo de residência gástrica. Prepararam-se, por meio do método de difusão-evaporação de solvente, microesferas de acetato de celulose, acrycoat
S100 e eudragit S100 carregadas com cloridrato de verapamil. As microesferas apresentaram superficies regulares, com propriedades de fluxo livre e de bom empacotamento. O rendimento das microesferas foi superior a 70,51\% e as microesferas de acetato de celulose captaram a quantidade máxima do fármaco. Microscopia eletrônica de varredura confirmou as cavidades em suas estruturas, com tamanhos na faixa de 251,80 a 350,75 $\mu \mathrm{m}$. As microesferas preparadas apresentaram liberação prolongada do fármaco e permaneceram flutuantes por mais que $12 \mathrm{~h}$. Imagens radiográficas do estômago de cão revelaram que as esferas de acetato de celulose carregadas com sulfato de bário flutuaram no fluido gástrico por, aproximadamente, 3,2 h. Estudos de liberação in vitro demonstraram difusão não-Fickiana dos fármacos das microesferas.

UNITERMS: Cloridrato de verapamil. Microesferas flutuantes.

\section{REFERENCES}

DESAI, S.; BOLTON, S. A floating controlled-release drug delivery system: in vitro-in vivo evaluation. Pharm. Res., v.10, p.1321-1325, 1993.

GARG, S.; SHARMA, S. Gastroretentive drug delivery systems. In: BUSINESS BRIEFING. PharmaTech., p.160-166, 2003.

IANNUCCELLI, V.; COPPI, G.; BERNABEI, M.T.; CAMERONI, R. Air compartment multiple-unit system for prolonged gastric residence. Part I. Formulation study. Int. J. Pharm., v.174, p.47-54, 1998.

KAWASHIMA, Y.; NIWA, T.; TAKEUCHI, H.; HINO, T.; ITOH, Y. Hollow microspheres for use as a floating controlled drug delivery system in the stomach.J. Pharm. Sci., v.81, p.135-140, 1992.

KORSEMEYER, R.W.; GURNY, R.; DOELKER, E. M.; BURI, P.; PEPPAS, N. A. Mechanism of solute release from porous hydrophilic polymers. Int. J. Pharm., v.15, p.25-35, 1983.

PASSERINI, N.; PERISSUTI, B.; ALBERTINI, B.; VOINOVICH, D.; MONEGHINI, M.; RODRIGUEZ, L. Controlled release of verapamil hydrochloride from waxy microparticles prepared by spray congealing. $J$. Control. Release, v.88, p.263-275, 2003. 
SINGH, B. M.; KIM, K. H. Floating drug delivery systems: an approach to controlled drug delivery via gastric retention. J. Control. Release, v.63, p.235-259, 2000.

SINHA, V. R.; AGRAWAL, M. K.; KUMRIA, R. Influence of formulation and excipient variables on the pellet properties prepared by extrusion spheronization. Curr. Drug Delivery, v.2, p.1-8, 2005.

SOPPIMATH, K. S.; KULKARNI, A. R.; AMINABHAVI, T. M. Development of hollow microspheres as floating controlled release systems for cardiovascular drugs. Drug Dev. Ind. Pharm., v.27, n.6, p.507-515, 2001
SRIVASTAVA, A. K.; RIDHURKAR, D. N.; WADHWA, S. Floating microspheres of cimetidine: formulation, characterization and in vitro evaluation. Acta Pharm., v.55, p.277-285, 2005.

THUMMEL, K. E.; SHEN, D. D. Design and optimization of dosage regimens: pharmacokinetic data. In: HARDMAN, J. G.; LIMBIREL, L. E.; GILMAN, A. G., eds. Goodman and Gilman's The pharmacological basis of therapeutics. New York: Mc. Graw Hill, 2001. p. 2020.

WHITEHEAD, L.; FELL, J. T.; COLLETT, J. H.; SHARMA, H. L.; SMITH, A. M. Floating dosage form: an in vivo study demonstrating prolonged gastric retention. J. Control. Release, v.55, p.3-12, 1998.

Recebido para publicação em 13 de setembro de 2006. Aceito para publicação em 23 de outubro de 2007. 